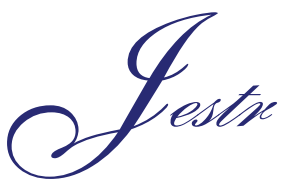

\title{
Analysis and Measurement of Buildability Factors Affecting Edge Formwork Labour Productivity
}

\author{
A. M. Jarkas \\ Mazaya Real Estate Development Co, KSCC, Projects \& Business Development Department \\ P.O. Box 3546, Safat 13036, State of Kuwait.
}

Received 24 January 2010; Revised 2 June 2010; Accepted 6 July 2010

\begin{abstract}
Labour productivity is affected by several factors, but buildability is among the most important. Nevertheless, a thorough examination of the literature revealed a dearth of research into the influence of buildability factors on labour productivity of in situ reinforced concrete construction, especially at the formwork trade level. Although edge formwork is an important labour intensive activity, most often, its labour cost is either crudely estimated or lumped within the formwork cost of other activities. Therefore, the objective of this research is to investigate and quantify the effects and relative influence of the following buildability factors on its labour productivity: (a) depth of slab being edge-formed; (b) slab geometric factor; and (c) type of formwork material used. To achieve this objective, a sufficiently large volume of productivity data was collected and analyzed using the multiple categorical-regression method. As a result, the effects and relative influence of the buildability factors investigated are determined. The findings show significant effects of these factors on edge formwork labour productivity, which can be used to provide designers feedback on how well their designs consider the requirements of buildability principles, and the consequences of their decisions on labour efficiency. On the other hand, the depicted patterns of results may provide guidance to construction managers for effective activity planning and efficient labour utilization.
\end{abstract}

Keywords: Buildability, Constructability, Edge formwork, Labour productivity, Rationalization, Standardization.

\section{Introduction}

Construction is the world's largest and most challenging industry [1]. In 1997, the US construction industry accounted for $10 \%$ of Gross Domestic Product (GDP) and employed over 10 Million, making the industry the largest in the country [2]. On the other hand, a $10 \%$ increase in construction labour productivity would yield annual savings of about $£ 1$ Billion to the British economy [3]; a similar conclusion was echoed by Stoekel and Quirke [4]. Since construction is a labour intensive industry, the significance of this influence, clearly justifies the concern over its labour productivity.

Several factors affect labour productivity, but buildability is one of the most important [3,5]. Buildability, as defined the Construction Industry Research and Information Association, is "the extent to which the design of a building facilitates ease of construction, subject to the overall requirements for the completed building" [6].

Design simplification is achieved through the implementation of the following three buildability principles: (1) rationalization; (2) standardization; and (3) repetition of elements [7]. Design rationalization is defined as "the minimization of the number of materials, sizes, components or sub-assemblies", whereas stand-

*E-mail address: jarkas@mazayarealestate.com

ISSN: 1791-2377 (C) 2010 Kavala Institute of Technology. All rights reserved. ardization is "a design philosophy requiring the designed product to be produced from those materials, components and subassemblies remaining after design rationalization has taken place" [8]. The design repetition principle involves repeating bay layout, floor grids, dimensions of elements, and storey height.

The influence of buildability on the construction process has been the subject of numerous previous investigations $[8,9,10$, $11,12,13,14,15,16,17,18,19,20,21]$ to name a few. However, a thorough examination of the literature revealed a dearth of research into the influence of buildability on the labour productivity of an integral trade of the in situ reinforced concrete material; namely, formwork. Moreover, most of previous buildability studies were heuristic in principles, generic and qualitative in nature; few were even rudimentary, based upon anecdotal perceptions, insights and common sense.

In the United States, as the case with most countries, the cost of formwork trade ranges from one-third to two-thirds of the overall cost of the reinforced concrete frame [22, 23], of which, the cost of labours comprises approximately thirty percent [24]. However, the influence of buildability on this trade, especially at the activity levels, is yet to be determined and quantified.

As the name indicates, edge formwork is an important ac- 
tivity, which is fixed at the slab perimeters, in accordance with the required depths, to contain the fresh concrete poured in place. Despite the importance of this activity to reinforced concrete construction, it is most often either roughly estimated, or lumped with other formwork activities through a subjective factor based upon previous experience and personal judgement of estimators. While such an approach may provide an estimate for this activity; it is at best, crude, and at worst, unreliable.

Therefore, the objective of this investigation is to quantify the effects and relative influence of the following buildability factors on edge formwork labour productivity: (a) depth of slab being edge-formed; (b) slab geometric factor; and (c) type of formwork material used. Consequently, labour productivity, hence labour cost and benefits related to the application of buildability principles, can be estimated for the various levels both, reliably and with reasonable accuracy.

To develop an understanding of previous research that had been conducted and the progress developed in the area of buildability, this paper starts with a relevant literature review of topics related to this study, briefly introduces an overview of the formwork trade, presents the research method and analysis, provides a discussion of the results obtained, and concludes with a recommendation geared towards encouraging further investigations into the influence of buildability on other elements and trades of in situ reinforced concrete construction.

\section{Literature Review}

In the most general term, productivity is an economic measure defined as the ratio of output to input [25]. Consequently, construction productivity can be regarded as a measure of outputs which are obtained by a combination of inputs. In view of this, two measures of construction productivity emerge: (1) total factor productivity, where outputs and all inputs are considered; and (2) partial factor productivity, often referred to as single factor productivity, where outputs and single or selected inputs are considered [26, 27].

The advantages of the single factor productivity, e.g., labour productivity, are many. By focusing on a selected factor, the measurement process becomes easier and more controllable. As a result, reliable and accurate data can be collected. The complex nature of the construction process and the interaction of its activities, make the labour productivity measure the popular option, especially for researchers, since effective control systems monitor each input separately. In addition, since construction is a labour intensive industry, it can be inferred that man-power is the only productive resource, thus construction productivity is mainly dependent upon human effort and performance.

Several factors affect labour productivity but, buildability is among the most important $[3,5]$. The word buildability, appears to have first entered the language in the late nineteen seventies [28]. An early attempt to address buildability can be credited to Sir Harold Emmerson [29] when he suggested a new form of relationship between designers and constructors. The point of concern was the lack of cohesion between designers and constructors and the inability of both parties to see the whole construction process through each other's eyes.
Constructors asserted it was the designers' fault and responsibility that the cost of buildings is high, and that the building designers were not enabling the clients to obtain the highest possible return value on their investment. Designers equally blamed the industry for not being able to realize their designs in the best economical way. Such a polemical argument has encouraged a major research effort into approaches to identify the root cause of the problem in order to bring design and construction professionals to work more closely together.

In an exploratory report, "Buildability: an assessment", published in 1983 by the Construction Industry Research and Information Association (CIRIA), buildability was tentatively defined, and perhaps it is the most widely accepted definition, as: "the extent to which the design of a building facilitates ease of construction, subject to the overall requirements for the completed building" [6].

Based on this definition, two implications may be inferred. First, buildability can be categorized in a scale ranging from good to bad; and second, each building has overall requirements which may conflict with the buildability concept, thus necessitate the acceptance of less than good buildability.

Throughout Europe, the expression "Buildability" is the adopted terminology for the influence of design on the construction process. On the other hand, the term "Constructability" is widely used and favoured in North America. The constructability task force of the Construction Industry Institute (CII) defines constructability as "the optimum use of construction knowledge and experience in planning, design, procurement, and field operations to achieve overall project objectives" [30]. Although both expressions target similar issues, the term constructability covers wider range of disciplines including conceptual planning, design, procurement and construction.

In attempts to enhance the understanding of the buildability concept, many researchers elaborated on the definition in their work. Illingworth [31] stated that the British construction industry would only be able to equal the efficiency of its global competitors by studying, and acting upon the requirements of buildability.

Ferguson [32] defined buildability as the ability to construct a building efficiently, economically, and to agreed quality levels from its constituent materials, components, and sub-assemblies. Griffith [20] suggested a compromise between consciously making the design more buildable and accommodating the many factors imparting an influence upon design including quality, aesthetics, time and cost.

Hyde [17] on the other hand, stated that the definition of buildability lacks precision when placed into operation in the design environment, and concluded that, buildability is not an absolute goal or quality as has been identified by many researchers, rather it is related to qualitative aspects of buildings and the level of complexity involved in the process. Therefore, a clear direction or modus operandi must be developed for buildability assessment, and that the knowledge should progress from operational principles to designers to achieve the level of buildability desired.

One of the barriers, and perhaps the most important, to the implementation of the buildability concept, is the difficulty in measuring its benefits to the construction industry; the industry still lacks methodologies to represent the requirements for buildability analysis and measurement [33]. The first attempt to meas- 
ure the influence of design on buildability was undertaken by the Building Research Station [34]. The operation of cranes on various construction sites was examined, and was concluded that "if the site layout, or the type of construction utilized make the crane operation difficult, then the whole construction process would be difficult and uneconomical'. However, such an attempt failed to quantify the difficulty level associated with the site layout or type of construction.

Another attempt by the Royal Institution of Chartered Surveyors (RICS) was a comparison between construction operations of the UK and the US, with emphasis on design and contractual procedures. They concluded that "design cannot be divorced from construction without major time and cost penalties" [35]. Once again, the magnitude of such time and cost penalties was not determined.

The Construction Industry Research and Information Association (CIRIA) program of research, identified a constraint for achieving good buildability by stating that "the achievement of good buildability depends on both designers and builders being able to see the whole construction process through each other's eyes" [6]. Having identified this constraint however, no suggestion on how to assess the achievement of good buildability was provided.

In an effort to facilitate the implementation of the constructability concept in the construction industry, the Construction Industry Institute [36] has developed 17 constructability concepts, which are grouped under the three main phases of the construction project: (1) conceptual planning; (2) design and procurement; and (3) field operations. While such an effort is most certainly a step in the right direction, the benefits of applying the related concepts to each phase of the project's life cycle are yet to be determined in tangible terms.

O'Connor et al. [21] and Alshawi and Underwood [19] discussed the negative effect of the variability of element sizes on the complexity of the construction process. However, their work was limited to general guidelines without any quantification of the impacts of such factors on construction productivity. Furthermore, Fischer and Tatum [16] identified critical design variables which are important for the buildability of structures. Such variables included dimensions and details of elements, e.g., width, length, depth, and type. Yet, the effects of such variables on construction productivity were not measured.

In an effort to measure the buildability of designs, the "Buildable Design Appraisal System" (BDAS), was established by the Construction Industry Development Board of Singapore [37]. The primary objective of the BDAS is to assess the influence of design on construction productivity. The BDAS presents a systematic numerical method to appraise the effects of design on site efficiency and productivity by means of calculating the "Buildable Score" of the design taking into consideration the level of simplicity, standardization, and the extent of the single integrated elements, i.e., combining related components into a single element. Indices are awarded for each type of architectural and structural systems based on the level of difficulty of the construction operation. Designs with high buildable scores suggest more efficient use of labour, hence higher labour productivity.

A major shortcoming of this appraisal system however stems from the lack of depth in which buildability was assessed. Buildable scores are awarded based on the overall structural type and construction method. Such an approach is too general in nature where the impacts of buildability factors require investigations in far greater depth to establish and quantify their effects on labour productivity.

Although the BDAS is the only available quantitative design appraisal tool to date, the scientific reliability of the methodology employed in developing the system's buildable scores is questioned. Buildable scores were obtained from inputs provided by government agencies, private consultants, and product manufacturers based on previous personal and group experience and judgment [7]. While such an approach can be regarded as good practice and common sense, the scientific method requires facts to be established and supported by rigorous research, measurement, and analysis. Furthermore, Poh and Chen [15], in an empirical study of 37 completed buildings, determined inconsistent patterns among buildable scores, labour productivity, and construction cost, thus went on to conclude that "while a design with a high buildable score will result in more efficient labour usage, the relationship between the buildable score and construction cost is less distinct".

In advocating for the implementation of buildability principles, CIRIA, [38] on the other hand, stated that the application of the rationalization and standardization concepts provides site efficiency, predictability, and better value for money. However, no direction was suggested on how to assess or quantify such benefits in measurable terms.

Even though seminal work has been developed, apart from the BDAS, in none of the mentioned examples, were there any quantified or quoted figures, or even a suggestion on how to assess the buildability impact on construction activities. In addition, previous research has not provided "specific" guidance on how to measure the buildability of a design. In one of the few text books entirely devoted to buildability, Ferguson [32] shows the breadth of factors which must be considered to make a design buildable and provides many examples of buildability problems and suggestions for improvements. While such suggestions allow the classification of buildability issues according to their level of details, they do not link buildability issues to "specific" design decisions.

The basic dilemma, the researcher argues, may be attributed to the methodology employed by most related previous research, where the effect of buildability was investigated on a generic basis, which has overlooked the important aspect of the current problem. A practical solution to the problem, the researcher suggests, especially in reinforced concrete construction projects, where the construction process of such structures are composed of various trades and activities, may be achieved through: (a) investigating and determining the effects and relative influence of buildability factors at the activity or component levels, i.e., foundations, grade beams, columns, walls, beams and slabs, which support and make up the building frame, and are common to each activity, so that the impacts of buildability on such trades and activities can be readily available to designers to provide specific guidance to a particular design decision on the one hand, and the collective effects upon the overall phenomenon of buildability on a global basis may be well supported, established, and understood, hence can be implemented with sufficient ease, on the other; and (b) quantifying such effects in measurable terms so that the tangible benefits of buildability principles may be realized, and thus formalized. 


\section{Formwork Trade Overview}

Formwork is used to obtain a shape in concrete. It includes the actual material in contact with concrete and all the necessary associated supporting structures. Formwork is removed in a process called striking or stripping.

Formwork is expensive Illingworth [23]. Therefore, it should be carefully handled and reused as many times as possible. In addition, standardization of dimensions, rationalization of design schemes, and repetition of element sizes throughout the project are essential to ensure efficient and cost-effective utilization of formwork materials.

Formwork types are grouped according to their application as follows [39]: (a) vertical formwork, where the concrete lateral pressure is the governing factor. Examples of this type involve columns, walls, and edges; and (b) horizontal formwork, where the weight of concrete is the governing factor. Suspended slabs, decks, and cantilever structures are prime examples of this type.

A wide variety of materials is used for formwork, e.g., timber, hardboard, steel, aluminium, geotextile fabric, glass fiber reinforced plastic (GRP), and a combination thereof. The most common material however is timber, also known as "traditional" formwork [40]. Timber has the advantage over all other materials, especially in low to medium-rise buildings, because it can be easily cut, handled, and assembled on site, however, may not be the most economical option if a high finishing quality is required and a high degree of repetition is involved, where the advantages of the metal and plastic types prevail [41]. Timber is used as bearers in soffit forms as well as waling in wall forms. Plywood is mainly used for panels. Both traditional and proprietary formwork use plywood, which is by far, the most common sheathing and soffit material used.

In view of the preceding discussion, it may be concluded that each type of the previously presented materials is associated with its own task-level difficulty, hence can also be an influential buildability factor on the labour productivity of the formwork operation. However, since slab edges are usually elements which do not require high finishing quality, in all sites observed, the traditional formwork, i.e., timber, was the type used for this activity.

Depending upon the depth of elements formed, edge formwork observed comprised fixing either plywood sheets or timber boards at the slab peripherals to contain the fresh concrete and establish the required level, thus the specified thickness of elements. Unlike plywood sheets, which come in standard sheet size of 1220 $\mathrm{mm}$ x $2440 \mathrm{~mm}$, timber boards comprise individual boards finished and cut to standardized widths and depths, commonly specified in inches, ranging from a minimum of 1" x 2" (19 mm x 38 $\mathrm{mm})$ to a maximum of 8 " 8 " (184 $\mathrm{mm} \times 184 \mathrm{~mm})$, require additional labour input to be assembled to the required size.

The major tasks of edge formwork observed, included placing sides in positions and in accordance with the peripheral slab geometries, lining, levelling, plumbing, and bracing in place. Since edge formwork is classified within the vertical category, where the concrete lateral pressure, rather than the weight, is the governing factor in the forming process, the complexity of the forming process is a function of the depth or thickness of elements.

Based on the previous discussion, it can be hypothesized that the following buildability factors impact the task level difficulty of edge formwork, thus the labour productivity of the operation: (a) depth of edge-formed slab; (b) peripheral slab geometry; and (c) type of formwork material used, i.e., plywood sheets vs. timber boards.

\section{Research Method and Analysis}

The relevant labour productivity data, which were part of a larger research project, were collected from sixty-eight different construction sites located in the State of Kuwait, where in situ reinforced concrete material is the prevailing type of construction. The data collection duration spanned a period of forty-nine months, in which, a total of 284 productivity data points were collected. Such a volume made it possible to achieve valid, reliable, and robust statistical results.

Since numerous factors, other than buildability, influence labour productivity on sites, which may mask or even overshadow the effect of buildability on the forming operation, the focus was on selecting construction projects which shared common features such as, contract procurement method, geographical locations, and to a large extent, construction methods, yet differed in types and magnitudes, so that the impacts of the explored buildability factors could be unravelled; similar sites, largely share similar characteristics of buildability factors, especially at the activity level, thus their influence may not be best revealed.

On the other hand, the differences in management procedures applied among the various types and magnitudes of sites monitored, at the project level, have little effect at the activity level of observation, whereas, the possible impacts of other interfering factors such as, crew size and composition, skill of labours, motivation, and supervision quality can be moderated by collecting a large volume of labour productivity data [42]. Consequently, sites observed included residential, office, and commercial buildings, industrial facilities, and warehouses.

In an effort to minimize the negative influence of interruptions and disruptions on labour productivity, major encountered delays during the forming process, e.g., material shortage, unavailability of tools, accidents, and inclement weather, were recorded and discounted, where only productive labour inputs were used to quantify the labour productivity indices.

The labour inputs for edge formwork observed were collected using the intermittent observation technique [42, 43]. A specifically designed data collection form was used in all sites monitored to systematically and consistently record the essential productivity parameters of the labour inputs, and to record the major delays encountered in the forming operation. The intermittent observation technique involved collecting labour inputs upon the completion of the activity, yet conducting occasional site visits during the process to ensure that data collection forms are filled out regularly, and assess the physical progress of activities under observation.

The data collected from crew leaders were cross-checked by both, superintendents and foremen, for verification and accuracy. In addition, edge-formed elements were visually inspected and marked on the related drawings for output measurements.

As previously stated, the buildability factors explored included: (a) depth of slab; (b) slab geometric factor; and (c) type of formwork material used. Commonly, slabs vary in depth in ac- 
cordance with spans and resisting loads. Therefore, the slab size factor was represented by the edge size fixed, which was quantified as shown in Equation 1.

$$
\begin{aligned}
& \text { Shutter Surface Area }\left(m^{2}\right)= \\
& =\text { Total perimeter length }(m) * \text { Edgedepth }(m)
\end{aligned}
$$

The complexity of the peripheral slab geometry depicted in Figure 1, was denoted by the "geometric factor" (GF), and was determined by the following mathematical relationship:
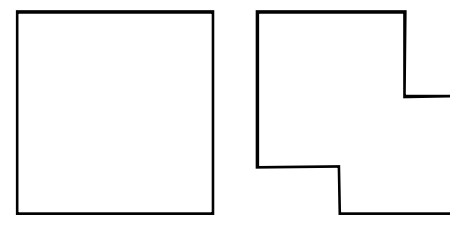

Increased Complexity
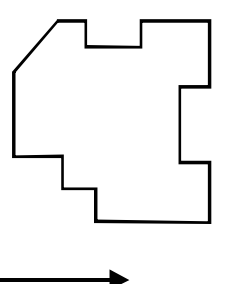

Figure 1. Increased Complexity Level of Peripheral Geometry of EdgeFormed Slabs

Geometric factor $=$

$=\frac{\text { Total number of angels around the perimeter }}{\text { Total perimeter length }(m)}$

The impact of the formwork material used, i.e., plywood sheets vs. timber boards, was quantified by introducing a binary "dummy" variable indicating the two types of formwork observed. The value of " 0 " was assigned to timber boards, and " 1 " for plywood sheets. The coefficient of the dummy variable in the categorical regression model quantifies the average difference in labour productivity between the two formwork types investigated.

All labour inputs collected were screened for possible measurement errors or outliers, i.e., an unusual observation which lies outside the range of the data values. On the other hand, the outputs of buildability factors explored were determined by the researcher using the "physical unit of measurement" technique [27]. The labour productivity indices for edge-formed slabs observed were then quantified as shown in Equation 3.

\section{Labour productivity $\left(\mathrm{m}^{2} / \mathrm{mh}\right)=$ \\ Area of edge forms erected $\left(\mathrm{m}^{2}\right)$ \\ Labour input (mh)}

The screened data were entered into a spreadsheet where the regression analyses were conducted, at 0.050 significance level, using the "PHStat" software, a statistics add-in for Microsoft ${ }^{\circledR}$ Excel. The normal probability plot of edge-formwork labour productivity data shown in Figure 2 reveals that the values belong to almost normally distributed populations, thus validating the statistical reliability inferences.

The effects and relative influence of the buildability factors investigated were analyzed using the multiple categorical-regression method [44, 45, 46, 47]. Since a multiple regression model involves several independent variables having different units of

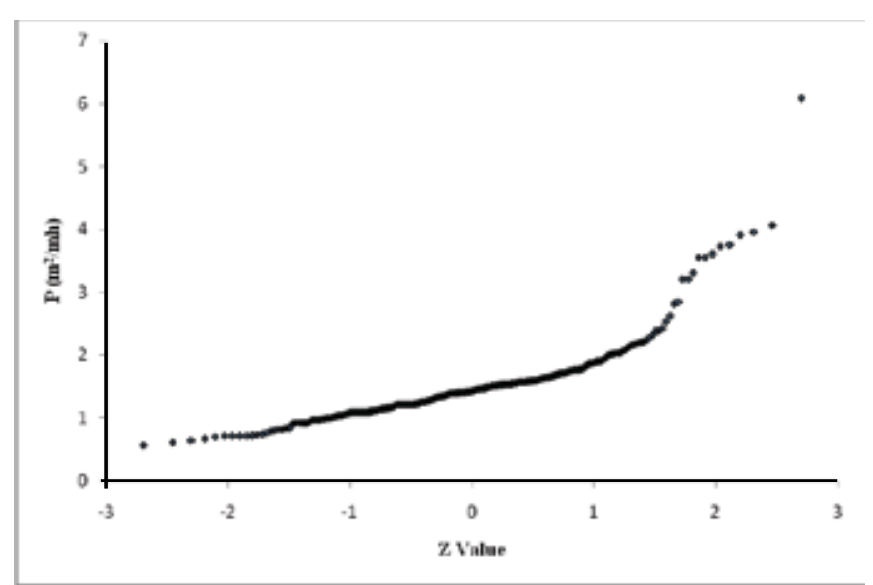

Figure 2. Normal Probability Plot of Edge-Formed Slab Labour Productivity

measurement, a direct comparison of the size of various coefficients to assess their relative influence on the dependent variable, could be spurious. Hence, continuous regression coefficients must to be standardized, thus are directly comparable to one another with the largest coefficient in absolute value indicating the greatest influence on the dependent variable. The regression coefficients were standardized using the following Equation [48]:

$$
b_{k}^{*}=b_{k}\left(\frac{s_{k}}{s_{y}}\right)
$$

Where $b_{k}^{*}$ is the standardized regression coefficient of the $k^{\text {th }}$ independent variable; $b_{k}$ is the regression coefficient of the $k^{\text {th }}$ independent variable; $s_{k}$ is the standard deviation of the $k^{\text {th }}$ independent variable; and $S_{y}$ is the standard deviation of the dependent variable. Commonly, standardized regression coefficients are referred to as "beta weights".

In addition, to determine the relative influence of such factors, the most influential factor was chosen to form the reference factor, and was assigned the value of 1.00 . The relative influence of each factor was then measured relative to the reference factor by the following formula:

$$
\begin{aligned}
& \text { Relative influence of the } k^{\text {th }} \text { factor }= \\
& =\frac{\text { Standardized coefficient value of the } k^{\text {th }} \text { factor }}{\text { Standardized coefficient value of the reference factor }}
\end{aligned}
$$

The reliability of the regression relationships was determined by conducting statistical significance tests at $5 \%$ significance level. The extent to which the data disagree with the null hypothesis, i.e., the regression coefficient of the corresponding buildability factor within the regression model is insignificantly different from zero, thus its effect on labour productivity is statistically insignificant, was determined by the p-value obtained for each factor investigated. The smaller the p-value of the corresponding factor, the greater the extent of disagreement between the data and the null hypothesis, and the more significant the result is. In general, if the $\mathrm{p}$-value of the regression coefficient is less than the significance level, i.e., $p$-value $<0.050$, the null hypothesis is rejected in favour 
of the alternate hypothesis, i.e., the impact of the corresponding buildability factor explored upon labour productivity is statistically significant [49].

Moreover, the goodness of fit of the regression models was assessed by the correlation and determination coefficients. The correlation coefficient, measures the strength of the linear correlation between the dependent and independent variables in the regression model, whereas the coefficient of determination indicates the percent of variance in the dependent variable which can be explained by the independent variables of the model. The higher the coefficients of correlation and determination in the regression model, the better the goodness of fit. The algebraic sign of the regression coefficient on the other hand, denotes the direction of the corresponding buildability factor's effect on labour productivity, i.e., positive or negative.

The relationship between the buildability factors explored and formwork labour productivity was determined by the multiple categorical-regression model shown in Equation 6:

$$
P\left(m^{2} / m h\right)=b_{0}+b_{1} S A+b_{2} G F+b_{3} F W T
$$

Where $S A$ is the surface area of edge forms fixed $\left(\mathrm{m}^{2}\right) ; G F$ is the slab geometric factor as determined by Equation 2, and $F W T$ is a dummy variable representing the two types of formwork observed. The value of " 0 " was assigned to timber boards, and " 1 " for plywood sheets.

The overall regression model and coefficients statistics are shown in Tables 1 and 2, respectively.

Table 1. Overall Regression Model Statistics for Edge Formwork Labour Productivity of Edge-Formed Slabs.

\begin{tabular}{lc}
\hline Correlation Coefficient $(\boldsymbol{R})$ & $89.97 \%$ \\
Coefficient of Determination $\left(\boldsymbol{R}^{2}\right)$ & $80.94 \%$ \\
Standard Error & 0.281 \\
$\boldsymbol{p}$-value & 0.000 \\
No. of Observations & 284 \\
\hline
\end{tabular}

Table 2. Regression Coefficients Statistics for Formwork Labour Productivity of Edge-Formed Slabs.

\begin{tabular}{|c|c|c|c|c|c|c|}
\hline Coefficient & Value & $\begin{array}{c}\text { Standard } \\
\text { Error }\end{array}$ & p-value & $V I F^{\prime}$ & $\begin{array}{c}\text { Standardized } \\
\text { Coefficient } \\
\text { Value }\end{array}$ & $\begin{array}{c}\text { Influence } \\
\text { Rank }\end{array}$ \\
\hline$S A\left(m^{2}\right)$ & 0.00364 & 0.000164 & 0.000 & 1.42 & 0.690 & 1 \\
\hline$G F$ & -1.33 & 0.0970 & 0.000 & 1.07 & -0.369 & 2 \\
\hline$F W T$ & 0.136 & 0.0487 & 0.00552 & 1.44 & $N / A^{2}$ & $N / A$ \\
\hline
\end{tabular}

${ }^{1}$ Variance inflation factor determines the level of correlation among the independent buildability factors in the model. A VIF value greater than 10 indicates severe multicollinearity, thus undermining the statistical results. ${ }^{2}$ Dummy variables are used to quantify differences in levels between or among categories, therefore, the normal interpretation for standardized coefficients does not apply.

Therefore, the relationship between edge formwork labour productivity and the relevant buildability factors was quantified as shown in Equation 7:

$$
\begin{aligned}
& P\left(m^{2} / m h\right)= \\
& =1.55+0.00364 S A-1.33 G F+0.136 F W T
\end{aligned}
$$

Table 1 shows strong correlation and high determination coefficients between the investigated factors and labour productivity, i.e., $89.97 \%$ and $80.94 \%$, respectively. Table 2 further shows that the regression coefficients of all buildability factors investigated are statistically significant in their effects on labour productivity, i.e., p-values of all factors are less than 0.050 . Therefore, the null hypothesis of each factor is rejected in favour of the alternate hypothesis. Moreover, the influence rank and relative influence values are shown, with the edge-form size factor being more influential than the slab geometric factor, on labour productivity.

In comparison with fixing timber boards, the regression coefficient of the categorical "dummy" variable, i.e., $F W T$, indicates a significant average gain of $0.136 \mathrm{~m} 2 / \mathrm{mh}$ in labour productivity as a result of fixing plywood sheets. In order to quantify the average percentage gain in labour productivity between the two types of formwork materials observed, the corresponding average values of the buildability factors shown in Table 3 were substituted into the regression model shown in Equation 7, for the two categories of formwork types, i.e., 0 and 1, as follows:

Table 3. Average Values of Buildability Factors Affecting Edge Formwork Labour Productivity.

\begin{tabular}{ccc}
\hline $\begin{array}{c}\text { Formwork } \\
\text { Material Type }\end{array}$ & $\begin{array}{c}\text { Average } \\
\text { Edge-Form Area } \\
\left(\mathbf{S A}\left(\mathbf{m}^{2}\right) \mathbf{)}\right.\end{array}$ & $\begin{array}{c}\text { Average Slab } \\
\text { Geometric Factor } \\
(\mathbf{G F})\end{array}$ \\
\hline $\begin{array}{c}\text { Timber Board } \\
\text { Sheets } \\
\text { Plywood Sheet } \\
\text { Panels }\end{array}$ & 9.88 & 0.182 \\
\hline
\end{tabular}

\section{A. Fixing Timber Boards, FWT $=0$ :}

$$
\begin{aligned}
& P\left(m^{2} / m h\right)= \\
& =1.55+0.00364(9.88)-1.33(0.182)+0.136(0)=1.34
\end{aligned}
$$

\section{B. Fixing Plywood Sheets, FWT = 1:}

$$
P\left(m^{2} / m h\right)=
$$$$
=1.55+0.00364(168.69)-1.33(0.079)+0.136(1)=2.19
$$

Therefore, the average difference in labour productivity was quantified as shown below:

$$
\left[\frac{(2.19-1.34)}{(1.34)}\right] * 100=63.43 \%
$$

Accordingly, in comparison with fixing timber boards, an average gain of approximately $63 \%$ in labour productivity, is associated with fixing plywood edge-form sheets. 


\section{Discussion of Results}

This study has determined the effects and relative influence of buildability factors on labour productivity of edge-formed slabs. Although the researcher could not identify previous quantitative research, with which to compare the findings of this investigation, the results obtained correlate with the buildability concept on the one hand, and fall within the design rationalization and standardization principles advocated for in previous studies [7, 16, 38], on the other.

The results obtained show a significant positive relationship between the area of edge formwork and labour productivity; as the area of edge forms increases by $1.00 \mathrm{~m}^{2}$, holding all other factors constant, labour productivity, on average, increases by 0.00364 $\mathrm{m}^{2} / \mathrm{mh}$.

The positive influence of the surface shutter area of edges on labour productivity may be ascribed the following four reasons: (1) an initial contributory time, e.g., setting out, reading drawings and details, is required by crew members to prepare work areas and formwork materials prior to commencing the direct or effective work. Therefore, if an activity is of a small-scale type, a major portion of the total input is directed towards contributory rather than direct work; (2) the researcher observed that it approximately takes the same input to shutter the edge, for instance, of a $150 \mathrm{~mm}$ thick slab as for $250 \mathrm{~mm}$; (3) when crew members are confronted with large scale activities, better preparation, planning and control is observed on sites; and (4) in large scale monitored activities, crew members tend to work harder and take less frequent breaks. In view of the aforementioned, such an effect may be referred to as "economy of scale".

In analyzing the influence of intersections, i.e., corners, on formwork productivity of walls, Smith and Hanna [50] compared the productivity of straight walls to those with intersections, and an average loss of approximately $48 \%$ in formwork productivity was quantified between the two categories due to the presence of such intersections. Furthermore, Smith et al. [51] investigated factors affecting formwork productivity of walls, and reported a substantial loss of productivity ranging in ratio from 1.10 to 2.00 in comparison with straight walls base rate due to the presence of corners in wall perimeters, which further corroborated the results obtained by Smith and Hanna [50].

Notwithstanding the difference between the two activities, the effect of slab peripheral geometry quantified by this investigation is in accordance with the pattern of the previous discussed findings. Holding the edge-form surface area constant, as the ratio of the total number of angles around the perimeter to the total length of the perimeter, i.e., slab geometric factor, increases by one unit, formwork labour productivity significantly decreases, on average, by $1.33 \mathrm{~m}^{2} / \mathrm{mh}$.

This pattern further confirms the importance of applying the rationalization and standardization principles to the design stage of construction projects. The activity would be much simpler and faster when formwork crew members fix edge forms with minimum interruptions resulting from constantly changing directions along the slab perimeter. Moreover, as the number of angles around the perimeter increases, more measurement, cutting and corner alignment is required.

It is important to re-emphasize however that, although the forming complexity of the slab peripheral geometry shown in Figure 1 has a direct influence on the labour productivity of the activity as determined by the outcomes of this study, the shape of a building periphery may be constrained by other factors which are beyond the control of the designer, e.g., plot boundaries, zoning regulations, or end-user requirements, and thus result in more complex configuration, which may otherwise be simpler under different circumstances or conditions. Nonetheless, it is further important to note that the implication of related outcome of this study is certainly not to curtail the design process or limit the construction innovation; simplicity should be rather progressive, not reactionary [52].

This investigation further substantiated the importance of formwork material on labour productivity, thus the project schedule. In comparison with plywood sheets, timber boards edge-formed slabs are associated with significant loss in labour productivity. Unlike plywood sheets, which come in a standard sheet size of $1220 \mathrm{~mm}$ x $2440 \mathrm{~mm}$, as previously indicated, and commonly are cut either off or on-site in half, i.e., $610 \mathrm{~mm}$ x 1220 $\mathrm{mm}$, for ease of handling and fixing, timber boards require an additional substantial amount of labour inputs to be assembled to the required depth of slabs prior to fixing.

Between the two types of formwork materials encountered on sites observed, i.e., timber boards and plywood sheets, holding all other factors constant, the related finding shows a significant average gain of $0.136 \mathrm{~m}^{2} / \mathrm{mh}$ in labour productivity associated with the latter type, in comparison with the former. Moreover, in comparison with slabs edged-formed using plywood sheets, the labour productivity of edge slabs formed by the timber-board type is, on average, 63\% lower, as determined by Equation 8. Such a significant loss in labour productivity, clearly demonstrates the importance of the formwork material selection to the efficiency of the operation.

\section{Conclusions and Recommendations for Further Research}

Due to the importance of in situ reinforced concrete material to the construction industry, this research focused on investigating the influence of buildability factors on the labour productivity of one of its major trade; namely, formwork. Despite the importance of edge formwork to in situ concrete slabs, the labour cost of this activity is most often, either crudely estimated, or lumped with the cost of other formwork activities. Therefore, this study has quantified the impacts of major buildability factors affecting its labour productivity, thus can help reducing the risk of labour costs overrun and increases the efficiency of this activity.

This investigation has quantified the effects of: slab edge thickness; peripheral geometric factor; and type of formwork material used, on edge formwork labour productivity. The explored buildability factors are found to be significant in their effects, which further substantiate the importance of applying the rationalization and standardization principles to the design stage of construction projects.

Notwithstanding that general buildability heuristic principles are available for designers, knowledge bases that support specific and timely buildability input to design decisions do not exist [16]. Consequently, such principles may be regarded as exhortations of 
good practice and common sense, often obtained using "Delphic Research Methods" [28]. Furthermore, most of the existing recommendations and suggestions for buildability improvement, the researcher argues, lack the supporting quantitative evidences, which lend little reliability to the extent to which such recommendations influence the productivity of the construction process on the one hand, and are often associated with scepticism, especially among design and construction practitioners, on the other. Conversely, the quantitative findings of this study are obtained through rigorous research and analysis, and thus can be used as supporting references for "formalizing" the specific buildability knowledge of this activity.

The outcomes of this study fill a gap in buildability knowledge and measurement of factors affecting edge formwork construction, which can be used to provide designers feedback on how well their designs consider the requirements of the buildability principles, and the consequences of their decisions on labour productivity. On the other hand, the depicted patterns of results may provide guidance to estimators, and construction managers, for reasonable cost estimation; effective activity planning, and efficient labour utilization, respectively.

Although several findings have been drawn from this study, further research into the effects of buildability factors on formwork, and other related trades of in situ reinforced concrete material, i.e., rebar fixing and concreting, labour productivity, which are common to other structural elements such as, foundations, walls, columns, beams, and slabs, is recommended. The findings of this investigation, in addition to other trades and structural elements recommended for exploration, can ultimately be used to develop an automated "Buildability Design Support System". Such a system would be useful for formalizing the specific buildability knowledge of in situ reinforced concrete construction, thus improving the performance of projects in an ever-increasing demand for faster and lower cost delivery of constructed facilities.

\section{References}

1. R. L. Tucker, "Management of Construction Productivity", ASCE Journal of Management in Engineering, 2, 148, (1986).

2. E. Allmon, C. T. Hass, J. D. Borcherding and P. M. Goodrum, "US Construction Labour Productivity Trends, 1970 - 1998". ASCE Journal of Construction Engineering and Management, 126, 97, (2000).

3. R. M. W. Horner, B. T. Talhouni and H. R. Thomas, "Preliminary Results of Major Labour Productivity Monitoring Programme", Proceedings of the $3^{\text {rd }}$ Yugoslavian Symposium on Construction Management, Cavtat, (1989).

4. A. Stoeckel and D. Quirke, "Services: Setting the Agenda for Reform", Industries Research Program, Department of Industry, Technology and Commerce, London, UK, (1992).

5. S. Adams, "Practical Buildability", Construction Industry Research and Information Association (CIRIA), Building Design Report, (1989).

6. Construction Industry Research and Information Association, CIRIA, "Buildability: An Assessment", CIRIA Publications, Special Report No. 26, (1983).

7. C. J. Dong, "Effects of Design on Buildability", M. Eng. Thesis, Nanyang Technological University, Singapore, (1996).

8. D. Moore, "Buildability, Prefabrication, Rationalisation and Passive Buildings in the UK", Association of Researchers in Construction Management, $12^{\text {th }}$ Annual Conference and Annual General Meeting, Conference Proceedings, Sheffield Hallam University, 1, 93, (1996b).

9. P. Lam and F. W. Wong, "Improving Building Project Performance: How Buildability Benchmarking can help", Construction Management and Economics, 27, 41, (2009).

10. E. Saghatforoush, S. Hasim, M. Jaafar and M. Abdul Kadir, "Constructability Implementation among Malaysian Building Contractors. European Journal of Scientific Research, 29, 518, (2009).

11. P. Lam, A. Chan, F. K. Wong and F. W. Wong, "Constructability Rankings of Construction Systems Based on the Analytical Hierarchy Process", ASCE Journal of Construction Engineering and Management, 13, $36,(2007)$.

12. B. Trigunarsyah, "Project Designers' Role in Improving Constructability of Indonesian Construction Projects", Construction Management and Economics, 25, 207, (2007).

13. B. Trigunarsyah, "Constructability Practices among Construction Contractors in Indonesia", ASCE Journal of Construction Engineering and Management, 130, 656, (2004).

14. M. H. Pulaski and M. J. Horman, "Organizing Constructability Knowl- edge for Design", ASCE Journal of Construction Engineering and Management, 131, 911, (2005).

15. P. Poh, and J. Chen, "The Singapore Buildable Design Appraisal System: a Preliminary Review of the Relationship between Buildability, Site Productivity and Cost", Construction Management and Economics, 16, 681, (1998).

16. M. Fischer and C. B. Tatum, "Characteristics of Design-Relevant Constructability Knowledge", ASCE Journal of Construction Engineering and Management, 123, 253, (1997).

17. R. Hyde, "Buildability as a Design Concept for Architects: A case study of Laboratory Buildings", Journal of Engineering, Construction and Architectural Management, 3, 45, (1996).

18. D. Moore, "Buildability Assessment and the Development of an Automated Design Aid for Managing the Transfer of Construction Process Knowledge", Journal of Engineering, Construction and Architectural Management, 3, 29, (1996a).

19. M. Alshawi and J. Underwood, "Improving the Constructability of Design Solutions through an Integrated System", Journal of Engineering, Construction and Architectural Management, 3, 47, (1996).

20. A. Griffith, "An Investigation into Factors Influencing Buildability and Levels of Productivity for Application to Selecting Alternative Design Solutions - A Preliminary Report", Managing Construction Worldwide, Chartered Institute of Building, CIOB, 2, 646, (1987).

21. J. T. O'Connor, S. E. Rusch and M. J. Schulz, "Constructability Concepts for Engineering and Procurement", ASCE Journal of Construction Engineering and Management, 113, 235, (1987).

22. M. K. Hurd, "Formwork for Concrete", $7^{\text {th }}$ Edition, SP-4, American Concrete Institute, Farmington Hills, Michigan, USA, (2005).

23. J. R. Illingworth, (2000) Construction Methods and Planning, $2^{\text {nd }}$ Edition, E \& FN Spon, London, (2000).

24. B. McTague and G. Jergeas, "Productivity Improvements on Alberta Major Construction Projects", Construction Productivity Improvement Report/Project Evaluation Tool, Alberta Economic Development, Canada, (2002).

25. J. Adrian, "Construction Productivity Improvement", Elsevier Science Publishing Co., (1987).

26. A. S. Rakhra, "Construction Productivity: Concept, Measurement and Trends", Organisation and Management in Construction, Proceedings of the $4^{\text {th }}$ Yugoslavian Symposium on Construction Management, Dubrovnik, 487, (1991). 
27. B. T. Talhouni, "Measurement and Analysis of Construction Labour Productivity”, Ph.D. Thesis, Department of Civil Engineering, University of Dundee, Dundee, UK, (1990).

28. D. W. Cheetham and J. Lewis, "Productivity, Buildability, and Constructability: is Work Study the Missing Link?" Association of Researchers in Construction Management, $17^{\text {th }}$ Annual Conference, University of Salford, 1, 271, (2001).

29. H. Emmerson, "Survey of Problems before the Construction Industries", A Report Prepared for the Ministry of Works, HMSO, London, UK, (1962).

30. Construction Industry Institute, CII, “Constructability: A primer”, University of Texas at Austin, Austin, Texas, USA, (1986).

31. J. R. Illingworth, “Buildability - Tomorrow's Need?” Building Technology and Management, February, 16, (1984).

32. I. Ferguson, "Buildability in Practice", Mitchell's Professional Library, London, UK, (1989).

33. Y. Song and D. Chua, "Modeling of Functional Construction Requirements for Constructability Analysis", ASCE Journal of Construction Engineering and Management, 132, 1314, (2006).

34. Building Research Station, BRS, "The use of Cranes on Low-Rise, High Density Industrialised Housing”, Current Paper 25/70, Watford, UK, (1970).

35. Royal Institution of Chartered Surveyors, RICS, "UK and US Construction Industries: A Comparison of Design and Contract Procedures”, Department of Construction Management, University of Reading, UK: 50, 86, (1979).

36. Construction Industry Institute, CII, "Constructability Implementation Guide", University of Texas at Austin, Austin, Texas, USA, (1993).

37. Construction Industry Development Board, CIDB, "Buildable Design Appraisal System", $3^{\text {rd }}$ Edition, Singapore, (1995).

38. Construction Industry Research and Information Association, CIRIA, "Standardisation and Pre-assembly: Adding Value to Construction Projects", CIRIA Report No. 176, (1999).

39. M. J. Ricouard, "Formwork for Concrete Construction", The Macmillan
Press Ltd., London, UK, (1982).

40. P. Brett, "Formwork and Concrete Practice", Heinemann Professional Publishing Ltd., London, UK, (1988).

41. R. L. Peurifoy, C. J. Schexnayder and A. Shapira, "Construction Planning, Equipment and Methods", $7^{\text {th }}$ Edition, McGraw-Hill, Boston, USA, (2006).

42. A. M. Jarkas, "An Investigation into the Influence of Buildability Factors on Productivity of in situ Reinforced Concrete Construction", Ph.D. Thesis, Department of Civil Engineering, University of Dundee, Dundee, UK, (2005).

43. I. Noor, "A Study of the Variability of Labour Productivity in Building Trades", Ph.D. Thesis, Department of Civil Engineering, University of Dundee, Dundee, UK, (1992).

44. D. N. Gujarati, "Basic Econometrics", McGraw-Hill, New York, USA, (1995).

45. C. H. Lawrence, "Regression with Graphics", Brooks/Cole, (1992).

46. W. Sanford, “Applied Linear Regression", $2^{\text {nd }}$ Edition, John Wiley \& Sons, (1985).

47. M. A. Hardy, "Regression with Dummy Variables", Sage University Papers, QASS No. 07-093, Newbury, California, Sage Publications, (1993).

48. J. Kim and G. Feree, "Standardisation in Causal Analysis", Sociological Methods and Research, 10, 187, (1981).

49. T. Sincich, D. M. Levine and D. Stephan, "Practical Statistics by Example using Microsoft Excel and Minitab", $2^{\text {nd }}$ Edition, Prentice Hall, Upper Saddle River, New Jersey, USA, (2002).

50. G. R. Smith and A. S. Hanna, "Factors Influencing Formwork Productivity", Canadian Journal of Civil Engineering, 20, 144, (1993).

51. G. R. Smith, J. D. Shumway and H. R. Thomas, "Productivity Influence Factors for Baseline Comparisons", Managing Construction Worldwide, Chartered Institute of Building (CIOB), W-65, Trinidad, 989, (1993).

52. M. T. Williamson, "Buildability - The Effect of Design Complexity on Construction Productivity", M.Sc. Dissertation, Department of Civil Engineering, University of Dundee, Dundee, UK, (1999). 